\title{
Effect of volume of physical activities on the self-esteem among undergraduates of a private university in Colombo Ranaweera, K.K.T.T. ${ }^{a^{*}}$ \& Gunawardena S. ${ }^{b}$ \\ * thiiliinii@gmail.com \\ a. Department of Physiotherapy, Faculty of Allied Health Sciences, General Sir John Kotelawala \\ Defence University, 10390, Sri Lanaka \\ b. American National College, Colombo 03,00300, Sri Lanka
}

\begin{abstract}
Participation in physical activities and sports has been identified as a factor, that influence self-esteem positively. However, other studies have shown that exercise only increased self-esteem with respect to body image. Many studies have focused on the effect of a particular exercise routine on self-esteem rather than physical activity in general. This study focused on identifying the effect of volume of physical activities on self-esteem among undergraduates of a private University in Colombo. A descriptive cross sectional study was designed with a sample size of 61 undergraduates recruited through snowball sampling. The self-administered International Physical Activity Questionnaire (Short form), Rosenberg selfesteem scale and demographic data questionnaire along with an information sheet, consent form and debrief form was sent online to undergraduates of a private University in Colombo. The mean age of the sample was 21.62 (2.2). The majority of the sample were minimally active (62.3\%) and the mean volume of total energy expenditure was $1356 \mathrm{MET}$ min/week which is below the HEPA category. The majority of the sample had a high level of self-esteem (82\%). A binary logistic regression analysis was carried out to examine the impact of BMI, total time spent in sitting and total volume of energy spent, on the level of self-esteem. The model accounted for only $18.3 \%-30.0 \%$ of variance in outcome. However, only total volume of energy spent showed a significant impact on predicting the level of self-esteem (Wald $=5.20, p<0.05)$. The odds of having a high self-esteem decreased with the total volume of energy spent. The undergraduates had a relatively good physical activity level and self-esteem. However, with the increase of volume of physical activity, self-esteem decreased significantly. Further research should be carried out to confirm the effect of body-esteem , body dissatisfaction, type of exercise, frequency of exercise, gender or other variables to decipher this relationship.
\end{abstract}

Keywords: physical activity; self-esteem; undergraduates 


\section{Introduction}

As the transition to University life is associated with a sudden change of the lifestyles of the students to a more independent at the same time, a more responsible one, there might be a psychological burden on the students to cope up with this transition (Greene et al., 2011; Kuruppuarachchi et al., 2002; Nguyen-Michel, Unger, Hamilton \& Spruijt-Metz, 2006; Bray \& Kwan, 2006; Bulley et al., 2009). Self-esteem is significantly positively associated with academic performance during university life and academic and social adjustment during transition to university life (Friedlander et al., 2007; Rosli et al., 2012). It is one major quality identified to be benefited from exercise (Antony \& Tomar, 2016; Davis, 2012; Ekeland et al., 2005).

\subsection{Physical activity}

Worldwide, approximately one quarter of the adult population and a majority of the adolescents are found to be inactive (WHO, 2019). Especially with the increased sedentary lifestyles in par with the technological advancements in modern activities including travelling, household chores, office work and even leisure time activities. Sedentary behaviours are defined as minimal physical activity of energy expenditure not exceeding 1.5 METs which includes mainly activities done in sitting (Owen et al., 2010). Physical activities can be structured or not. Structured activities include exercise routines such as aerobics, playing sports or games. On the other hand, unstructured activities are the activities carried out in day to day life such as washing, cleaning or even stair climbing. These physical activities can be categorized as moderate and vigorous activities. Moderate intensity activities require an extra effort which would result in a noticeable increase of the heart rate. Examples of moderate intensity activities include brisk walking, gardening, sweeping and carrying light loads. Vigorous intensity activities require considerable effort that would result in increased heart rate, breathing rate and depth such as running, swimming and carrying heavy weights (WHO, 2019). The recommended physical activity level for adults between 18- 64 years of age is a minimum of 150 minutes per week of moderate intensity activities and 75 minutes of vigorous intensity activities (Global Recommendations on Physical Activity for Health, 2010).

\subsection{Self-esteem}

Self-esteem is the evaluation of one's worth (Antony \& Tomar, 2016; Davis, 2012; Ekeland et al., 2005). The Exercise and Self Esteem model has been proposed to explore the effect of physical activity and related measures which are consequences of the said physical activity including weight and physical fitness on global self-esteem among elderly. When this model was applied to the college population, physical selfesteem was identified as the major link between physical exercise and quality of life (Joseph et al., 2014)

\subsection{Physical activity and self-esteem among undergraduates}

Participation in physical activities and sports has been identified as a factor, that influence self-esteem positively (Kirkcaldy, Shephard, \& Siefen, 2002; Antony \& Tomar, 2016; Yịğiter, 2014). Undergraduates who had participated in physical activities for more than 4 hours per week had shown better self-esteem (Antony \& Tomar, 2016). Even though some studies have shown that exercises help increase self-esteem and self-confidence significantly other studies have shown that exercise only increased self-esteem with respect to body image. (Strelan \& Hargreaves, 2005). Men have linked physical fitness with self-esteem, while different exercise interventions have had a substantially different effect on self-esteem of women (Strelan \& Hargreaves, 2005; Furnham et al., 2002; Salamuddin et al., 2014). Particularly, female undergraduates who struggled with body image dissatisfaction didn't show a significant improvement in self-esteem in contrast to their male counterparts (Lowery et al., 2005). A systematic review of 23 
randomized controlled trials on the impact of exercise alone on self-esteem in adults and children found that short-term advantages can only be achieved. (Ekeland et al., 2005).

Still, many studies have focused on the effect of a particular exercise routine on self-esteem rather than physical activity in general. Specifically, step-dance aerobics and strength training have had beneficial effects on self-esteem among female students (Salamuddin et al., 2014). The presence of an instructor or being in a group has negatively influenced self-esteem (Fox, 2000). It was explained as a hindrance to personal growth due to the cognitive dissonance to adapt to the needs and attitudes of the instructor or the rest of the group. Nevertheless, when compared with weight training and running, weight training had shown significantly more improvements in self-esteem among female undergraduates (Trujillo, 1983). A study conducted among Sri Lankan school children who engaged in sports and particularly vigorous sports had reported a higher self-esteem level when compared with students who did not engage in any sports (Welhenge et al., 2018). Interestingly, there was no significant difference between the students who engaged in vigorous and light sports activities.

\section{Methodology}

Students of a private University was selected according to the convenience of the researcher due to limited access to students within a short period of time. The sampling method was snowball sampling under purposive sampling method. Ethical clearance for the study was obtained from the Ethics Review Committee of University of West London. Permission for data collection was obtained from the Human Resource Department of the American National College. An information sheet and consent form was sent to the students from the Human Resource Department to participate in the study. Sixty-one students who had given informed consent was chosen to participate in the study.

Three questionnaires including demographic data, International Physical Activity Questionnaire (short version) (IPAQ-SF) and Rosenberg Self-esteem scale was sent to the students online.

\subsection{International Physical Activity Questionnaire (short version)}

The intensity of physical activities in walking, moderate intensity activities and vigorous intensity activities were calculated in MET (Metabolic Equivalent of Task)- minutes per week by multiplying the minutes spent in the particular activity by the number of days per week. The minutes per week was further multiplied by one MET equivalent for each activity as given below.

- Walking MET-minutes/week $=3.3 *$ walking minutes $*$ walking days

- $\quad$ Moderate MET-minutes/week $=4.0 *$ moderate-intensity activity minutes $*$ moderate days

- Vigorous MET-minutes/week $=8.0 *$ vigorous-intensity activity minutes $*$ vigorous-intensity days

The undergraduates were further classified as inactive, minimally active or HEPA (health enhancing physical activity) according to the volume of physical activity undertaken. HEPA category had students who reported a minimum of $1500 \mathrm{MET}$-minutes/week of vigorous activity in 3 days per week or a minimum of 3000 MET-minutes/week with any physical activity during the whole week. Minimally active category had students who reported a minimum of $600 \mathrm{MET}-\mathrm{min} /$ week with any physical activity or 30 minutes of moderate intensity activities during five or more days of the week or 20 minutes of vigorous activity during 3 or more days of the week. The students who didn't meet the above criteria was categorized as inactive.

\subsection{Rosenberg self-esteem scale}

Rosenberg self-esteem scale consisted of 10 questions regarding self-esteem, considering negative and positive feelings marked on a 4-point Likert scale from "strongly disagree" to "strongly agree". Out of the ten statements, 2, 5, 6, 8, 9 items are reverse coded. A score between 0-30, where a score less than 15 
indicated low self-esteem, was given by the Rosenberg self-esteem questionnaire.

\section{Results}

\subsection{Demographic data}

The mean age of the sample was $21.62(2.2)$. Majority $(65.6 \%, \mathrm{n}=40)$ of the sample were females. The religion and ethnicity of the majority of undergraduates were Buddhism $(83.6 \%, \mathrm{n}=51)$ and Sinhalese $(96.7 \%, \mathrm{n}=59)$. All the participants were Sri Lankans. Gross monthly income of most $(57.4 \%)$ of the families of the participants was more than 200,000 Sri Lankan Rupees. The mean weight and height of the participants in the sample were $59.61 \mathrm{~kg}(12.99)$ and $164.33 \mathrm{~cm}(13.38)$ respectively. Majority $(54.1 \%$, $\mathrm{n}=33$ ) of the sample had an appropriate Body Mass Index (BMI). The participants who fell into the overweight $(23 \%, \mathrm{n}=14)$ and underweight $(21.3 \%, \mathrm{n}=13)$ category were less than one fifth of the sample.

\subsection{Physical activities of undergraduates}

The current physical activities of the participants varied from aerobics $(42.6 \%, \mathrm{n}=26)$, sports $(27.9 \%$, $\mathrm{n}=17)$, resistance training $(11.5 \%, \mathrm{n}=7)$ and other activities $(9.8 \%, \mathrm{n}=6)$ that were unspecified. Five participants $(8.2 \%)$ stated that they didn't participate in any activity. Majority $(62.3 \%, n=38)$ of the undergraduates were minimally active while almost equal number of participants were in the inactive $(19.7 \%, \mathrm{n}=12)$ and HEPA $(18 \%, \mathrm{n}=11)$ categories. The mean time spent in sitting was 7.28 hours $(+6)$. Total energy spent in walking had a mean value of 601.84 MET-min/week while the total energy spent in moderate intensity activities was $588.78 \mathrm{MET}-\mathrm{min} /$ week. The vigorous intensity activities showed a mean of $480 \mathrm{MET}-\mathrm{min} /$ week while the total energy expenditure showed a mean of $1356 \mathrm{MET}$-min/week.

\subsection{Self-esteem}

The mean score of self-esteem was 17.11(4.60). The scores ranged from 4-29. Majority ( $82 \%, \mathrm{n}=50)$ had a high self-esteem.

Table 1. Frequency and percentage of undergraduates in different categories of demographic variables, physical activity level and self-esteem level

\begin{tabular}{|c|c|c|c|}
\hline Variable & Categories & Frequency & Percentage (\%) \\
\hline \multirow[t]{2}{*}{ Gender } & Female & 40 & 65.6 \\
\hline & Male & 21 & 34.4 \\
\hline \multirow[t]{3}{*}{ Religion } & Buddhism & 51 & 83.6 \\
\hline & Christianity & 8 & 13.1 \\
\hline & Other & 2 & 3.3 \\
\hline \multirow[t]{3}{*}{ Ethnicity } & Sinhalese & 59 & 96.7 \\
\hline & Tamil & 1 & 1.6 \\
\hline & Burgher & 1 & 1.6 \\
\hline \multirow[t]{3}{*}{ Gross monthly income of the family } & $100,000-149,999$ & 17 & 27.9 \\
\hline & $150,000-199,999$ & 9 & 14.8 \\
\hline & $>200,000$ & 35 & 57.4 \\
\hline \multirow[t]{4}{*}{ Body Mass Index } & Underweight & 13 & 21.3 \\
\hline & Normal & 33 & 54.1 \\
\hline & Overweight & 14 & 23 \\
\hline & Obese & 1 & 1.6 \\
\hline \multirow[t]{2}{*}{ Current physical activities } & Sports & 17 & 27.9 \\
\hline & Resistance training & 7 & 11.5 \\
\hline
\end{tabular}




\begin{tabular}{|c|c|c|c|}
\hline & Aerobics & 26 & 42.5 \\
\hline & Other (unspecified) & 6 & 9.8 \\
\hline & None & 5 & 8.2 \\
\hline \multirow[t]{3}{*}{ Physical activity level } & Inactive & 12 & 19.7 \\
\hline & Minimally active & 38 & 62.3 \\
\hline & HEPA & 11 & 18 \\
\hline \multirow[t]{2}{*}{ Self esteem } & High & 50 & 82 \\
\hline & Low & 11 & 18 \\
\hline
\end{tabular}

3.4 Impact of physical activity level on the level of self esteem

A binary regression analysis was carried out to examine the impact of BMI, total time spent in sitting and total volume of energy spent, on the level of self-esteem. The crude estimation table showed that the model will correctly predict the outcomes of $82 \%$ of the cases which was similar to the actual estimation. The model accounted for only $18.3 \%-30.0 \%$ of variance in outcome. The model fit was assessed using Omnibus test and Hosmer and Lemeshow test. The Omnibus test was significant $(p<0.05)$ and the Hosmer and Lemeshow test was not significant $(\mathrm{X} 2(8)=5.56, \mathrm{p}>0.05)$, that indicated a good model fit. However, only total volume of energy spent showed a significant impact on predicting the level of self-esteem (Wald= $5.20, \mathrm{p}<0.05)$. The $\operatorname{Exp}(\mathrm{B})$ or odds ratio was 0.999 , meaning for every increase in 'unit' of total amount of energy spent during a week the odds of having a high self-esteem decreased by a factor of 0.999 .

\section{Discussion}

The participants of this study showed that the level of self-esteem could be negatively affected by the volume of physical activities in terms of total energy spent. Similar results were observed in a control group of female undergraduates, where they engaged in miscellaneous physical activities other than weight training and running which were allocated for the subject group (Trujillo, 1983). Most (42.5\%, $n=26)$ of the participants of this sample took part in aerobic activities. Aerobic running even with a facilitator had failed to improve self-esteem of undergraduates (Rainey, \& Wigtil, 1985). A previous study had showed that only step-dance aerobics significantly improved self-esteem among female undergraduates (Salamuddin, Harun \& Al-Rashed, 2014). Only seven (11.5\%), of the participants participated in resistance training. Twenty-three (37.7\%) participants had participated in sports and other unspecified activities. Even among men in contrast to women in another study, increase of exercise levels had led to reduction of level of self-esteem (Joiner \& Tickle, 1998).

Another factor may be due to the fact that exercise improved body esteem rather than global self-esteem (Strelan \& Hargreaves, 2005). Especially among females, exercise didn't significantly improve self-esteem in previous studies also (Rivers, \& Dilger, 2015). As the sample of this study had a majority of females may be the results were biased. Some studies have shown no significant effect of exercise on self-esteem. The mean volume of total energy expenditure was $1356 \mathrm{MET}-\mathrm{min} /$ week which is below the HEPA category. The guidelines given by American College of Sports Medicine for physical activities include at least $600 \mathrm{MET}-\mathrm{min} /$ week of moderate intensity activities or $4800 \mathrm{MET}-\mathrm{min} /$ week of vigorous intensity activities (Bhochhibhoya et a., 2014). Only eleven undergraduates were included in the HEPA category. As majority of the students were in the minimally active group, the lack distribution of data in the two ends might also have affected the result. Previous studies among undergraduates have shown higher frequencies of students in inactive and HEPA groups. Especially the inactive group has been considerably higher in previous studies usually more than $30 \%$ of the sample (Bhochhibhoya et al., 2014). Among regular exercisers, body image was a significant predictor of self-esteem when compared with the non- exercising counterparts. Therefore, exercise habits were strongly associated with poor emotional well-being (Davis, 1990). 


\section{Conclusion and Limitations}

Overall, this study identified that the majority of the undergraduates were minimally active. Even though the frequency of inactive participants was relatively low, the participants in the HEPA category were also low. Most of the students engaged in aerobic activities as the form of physical activity. Majority of the sample had a high level of self-esteem There was a significant effect of physical activity intensity on the odds of reducing self-esteem Further studies are needed to confirm the effect of type of exercise, frequency of exercise or other variables to decipher this relationship.

Regarding methodological issues in data collection, all the questionnaires were self-administered online that might have left room for more optimistic and positive answers to be recorded deviating from the actual facts. Further, data was collected during a global pandemic which may have affected the psychological and physical states of the undergraduates compared to their normal routines. As the sampling method was convenience sampling, a non-probability sampling method, a barrier to generalize the results to the population and lack of normal distribution of data was observed. The power calculation gave a relatively small sample size. This study was a cross sectional study which limited comparisons between groups of different levels of physical activity, due to a smaller number of participants in some groups. A case control study would have helped to obtain more information comparing among the three groups of physical activity levels.

\section{Acknowledgement}

I would like to extend my gratitude to University of West London and American National College for their support to carry out this study.

\section{References}

Antony, V., \& Tomar, R. 2016. Effect of Sixteen Weeks of Fartlek Training on Self- Esteem of Saudi University Students. Indian Journal Of Science And Technology, 9(47). doi: 10.17485/ijst/2015/v8i1/103369

Bhochhibhoya, A., Branscum, P., Taylor, E.L. \& Hofford C. 2013. Exploring the Relationships of Physical Activity, Emotional Intelligence, and Mental Health among College Students. American Journal of Health Studies, 28(2), 17-57

Bray, S., \& Kwan, M. 2006. Physical Activity Is Associated With Better Health and Psychological Well-Being During Transition to University Life. Journal Of American College Health, 55(2), 77-82. doi: 10.3200/jach.55.2.77-82

Bulley, C., Donaghy, M., Payne, A., \& Mutrie, N. 2009. Personal meanings, values and feelings relating to physical activity and exercise participation in female undergraduates: A qualitative exploration. Journal of health psychology, 14(6), 751-760.

Davis C., 1990. Body image and weight preoccupation: A comparison between exercising and non-exercising women. Appetite. 15:13-21

Ekeland, E., Heian, F. \& Hagen K.B. 2005. Can exercise improve self esteem in children and young people? A systematic review of randomised controlled trials. Br J Sports Med; 39:792-798. doi: 10.1136/bjsm.2004.017707

Fox, K.R. 2000.The Effects of Exercise on Self-Perceptions and Self-Esteem. Physical Activity and Psychological Well-Being, Routledge, London, 88-117.

Friedlander, L. J., Reid, G. J., Shupak, N., \& Cribbie, R. 2007. Social support, self-esteem, and stress as predictors of adjustment to university among first-year undergraduates. Journal of college student development, 48(3), 259-274.

Furnham, A., Badmin, N., \& Sneade, I. 2002. Body Image Dissatisfaction: Gender Differences in Eating Attitudes, Self-Esteem, and Reasons for Exercise. The Journal Of Psychology, 136(6), 581-596. doi: 10.1080/00223980209604820

Greene, G., Schembre, S., White, A., Hoerr, S., Lohse, B., \& Shoff, S. et al. 2011. Identifying Clusters of College Students at Elevated Health Risk Based on Eating and Exercise Behaviors and Psychosocial Determinants of Body Weight. Journal Of The American Dietetic Association, 111(3), 394-400. doi: 10.1016/j.jada.2010.11.011

Global Recommendations on Physical Activity for Health. 2010.

Joiner, T.E., Tickle, J.J. 1998. Exercise and Depressive and Anxious Symptoms: What Is the Nature of Their Interrelations?. J Occup Rehabil 8, 191-198. https://doi.org/10.1023/A:1021326406744

Joseph, R. P., Royse, K. E., Benitez, T. J., \& Pekmezi, D. W. 2014. Physical activity and quality of life among university students: exploring self-efficacy, self-esteem, and affect as potential mediators. Quality of life research: an international journal of quality of life aspects of treatment, care and rehabilitation, 23(2), 659-667. https://doi.org/10.1007/s11136-013-0492-8

Kirkcaldy BD, Shephard RJ, Siefen RG. 2002. The relationship between physical activity and self-image and problem behavior among adolescents. Social Psychiatry and Psychiatric Epidemiology. 37(11):544-50. 
Kuruppuarachchi, K.A.L.A., Kuruppuarachchi, K.A.J.M., Wijerathne, S., \& Williams, S.S. 2002. Psychological distress among students from five Universities in Sri Lanka. The Ceylon Medical Journal, 47(1), 13-15.

Lowery, S., Kurpius, S., Befort, C., Blanks, E., Sollenberger, S., Nicpon, M., \& Huser, L. 2005. Body Image, Self-Esteem, and HealthRelated Behaviors Among Male and Female First Year College Students. Journal Of College Student Development, 46(6), 612-623. doi: $10.1353 /$ csd.2005.0062

Nguyen-Michel, S., Unger, J., Hamilton, J., \& Spruijt-Metz, D. 2006. Associations between physical activity and perceived stress/hassles in college students. Stress And Health, 22(3), 179-188. doi: 10.1002/smi.1094

Owen, N., Healy, G.N., Matthews, C.E. and Dunstan, D.W., 2010. Too much sitting: the population-health science of sedentary behavior. Exercise and sport sciences reviews, 38(3), p.105.

Physical Activity. 2019. https://www.who.int/dietphysicalactivity/pa/en/

Physical Activity Guidelines Advisory Committee. 2018. Physical Activity Guidelines Advisory Committee Scientific Report. Washington, DC: U.S. Department of Health and Human Services, 2018.

Rivers, C., \& Dilger, J. 2015). The Effects of Exercise on Self-Esteem, General Happiness, and Body Image.

Rosli, Y., Othman, H., Ishak, I., Lubis, S. H., Saat, N. Z. M., \& Omar, B., 2012. Self-esteem and academic performance relationship amongst the second year undergraduate students of Universiti Kebangsaan Malaysia, Kuala Lumpur Campus. Procedia-Social and Behavioral Sciences, 60, 582-589.

Rainey, D., \& Wigtil, J., 1985. Aerobic running as a counseling technique for undergraduates with low self-esteem. Journal of College Student Personnel, 26(1), 53-57.

Salamuddin, N., Harun, M., \& Al-Rashed, S., 2014. The Effects of Selected Aerobic Exercise Modalities on Self Esteem among Female Students. Asian Social Science, 10(5). doi: 10.5539/ass.v10n5p141

Strelan, P., \& Hargreaves, D., 2005. Reasons for Exercise and Body Esteem: Men's Responses to Self-Objectification. Sex Roles, 53(7-8), 495-503. doi: 10.1007/s11199-005-7137-5

Trujillo, C. M. 1983. The effect of weight training and running exercise intervention programs on the self-esteem of college women. International Journal of Sport Psychology, 14(3), 162-173.

Welhenge, C.U., Wickramanayake, D.S., Wickramasekara, M.H.M., Wijayarathne, W.A.L.T., Wijeratne, N.G., Zangmo, L. and Kasturiratne, A., 2018. Extra-curricular activities and self-esteem of school children in the Colombo District.

Yiğìter, K. 2014. The Effects of Participation in Regular Exercise on Self-Esteem and Hopelessness of Female University Students. Social Behavior And Personality: An International Journal, 42(8), 1233-1243. doi: 10.2224/sbp.2014.42.8.1233 